\title{
ERGODESIGN DE LIMA ENDODÔNTICA ASSOCIADO AO FIO DENTAL DURANTE A INSTRUMENTAÇÃO DE CANAIS RADICULARES
}

\section{ERGODESIGN OF ENDODONTIC FILE ASSOCIATED TO DENTAL FLOSS ON ROOT CANAL INSTRUMENTATION}

\author{
Vera Lúcia Lacerda Medeiros ${ }^{1}$, Cirurgiã-Dentista \& Advogada \\ Henrique Costa Braga ${ }^{2}$, M.Sc.
}

(1)e-mail: medeiros.veralu@gmail.com

(2) Departamento de Pós-Graduação em Modelagem Matemática e Computacional, CEFET-MG

e-mail: bragaseg@yahoo.com.br

Ergodesign, Lima Endodôntica, Fio Dental

\begin{abstract}
O ergodesign da lima endodôntica manual para suas atribuições, facilita sua associação ao fio dental, trazendo maior segurança ao paciente e ao profissional, quanto à ocorrência de acidente. Ao paciente, ao promover o impedimento de deglutição ou aspiração desse instrumento se este cair em região orofaríngea, especialmente quando o paciente se encontra posicionado de forma não adequada, facilitando a ocorrência do acidente, bem como o fato de não estar usando o lençol de borracha, ou como complemento a este. Portanto, utilizando o recurso, ainda em tempo pode-se resgatar a lima pelo fio dental. Quanto ao profissional, este evita posteriores complicações quanto ao fator ético legal. Este trabalho visa melhor esclarecer esses pontos, incentivando uma maior conscientização e discussão do assunto.
\end{abstract}

\section{Ergodesign, Endodontic File, Dental Floss}

The ergodesign of an endodontic manual file, concerning its attributions, turns the dental floss association easier, what brings more security to the patient and to the professional against accidents. About the patient, it prevents the file swallowing or aspiration, in case it falls in oropharyngeal region, when the patient is not on an ergonomic adequate position, or even if they are not using the rubber dam, or as a complement. Therefore, using this device, the dentist can rescue the file by holding the dental loss and prevent an accident. About the professional, the design avoids ethical and legal sues. This work aims to better clarify these points, encouraging a greater awareness and discussion of the subject. 


\section{$16^{\circ}$ \\ ERGODESIGN USIHC CINAHPA}

\section{Introdução}

Na prática da odontologia curativa, se faz rotineiramente necessário que o profissional atue diretamente na boca do paciente em diversos procedimentos, fazendo o uso e o manuseio de instrumentos que geralmente são de dimensões muito reduzidas. Um risco de acidente que pode ocorrer é que estes instrumentos podem se soltar, por exemplo, da mão do profissional, vindo a cair na boca do paciente. Se o instrumento for para a região orofaríngea, pode ocorrer a deglutição, ou até mesmo a aspiração deste instrumento.

Embora a ocorrência deste tipo de acidente seja por alguns considerados como sendo "relativamente pequena" [SILVA et al., 2010a], este tipo de acidente não deve ser de forma alguma desconsiderado. Infelizmente, existem muitos relatos de casos de acidentes relacionados à deglutição e a aspiração de instrumentos odontológicos [LAMBRIANIDIS, BELTES, 1997; SILVA et al., 2009; KATAOKA et al., 2011; RODRIGUES et al., 2012; POLETO et al., 2013; KHETANI et al., 2016]. Assim, deixa-se claro que este é um risco real, não devendo ser subestimado.

Quando da sua ocorrência, este fato pode até mesmo colocar a saúde do paciente em risco. Além disso, o transtorno em procedimentos médicohospitalares e a onerosidade para o profissional de odontologia, no sentido de ser contornada a situação provocada em decorrência desse tipo de acidente, pode ser vultoso ou até mesmo traumático. Existe inclusive a real possibilidade da ocorrência de eventuais querelas legais [SILVA et al., 2010b], de se infringir o Código de Ética Odontológica [CFO, 2012], ou quanto à bioética [ROVIDA, GARBIN, 2013].

Na odontologia a possibilidade de inesperados acidentes desta natureza associa-se a quase todas as especialidades, porém, neste trabalho é dado ênfase à endodontia. Esta especialidade é responsável pelo estudo, prevenção e tratamento das afecções pulpares e dos seus efeitos no periápice, sendo que seu surgimento como especialidade se deu nos estudos do chamado $16^{\circ}$ Ergodesign - Congresso Internacional de Ergonomia e Usabilidade de Interfaces Humano Tecnológica: Produto, Informações Ambientes Construídos e Transporte

$16^{\circ}$ USIHC - Congresso Internacional de Ergonomia e Usabilidade de Interfaces Humano Computador

CINAHPA | 2017 - Congresso Internacional de Ambientes Hipermídia para Aprendizagem.

tratamento de canal radicular [PRATS, 2005].

$\mathrm{Na}$ endodontia, o principal instrumento a ser usualmente manuseado é a lima endodôntica manual. Por se tratar de um instrumento perfurocortante, são graves os potenciais riscos à saúde do paciente numa deglutição ou aspiração por acidente desse instrumento. Entretanto, chama a atenção que a lima endodôntica manual já possua um recurso próprio disponibilizado pelo seu design, que se trata de um orifício no seu cabo.

Por este orifício existente é possível adaptar um fio dental para melhor proteção durante o desempenho dos procedimentos de instrumentação. Esta prática é muito menos trabalhosa que a realização de um total isolamento por meio de uma proteção por lençol de borracha, apesar de que a mesma deve ser vista como um complemento e não uma substituição ao uso do lençol. Adicionalmente, quando do uso do lençol de borracha, os grampos usados neste também devem ser amarrados com o fio dental [DE DEUS, 1992, p. 270].

No entanto, apesar de recomendado [SARAF et al., 2012; BONDARDE et al., 2015], alguns profissionais podem não estar realizando este procedimento com as limas endodônticas manuais. Uma discussão mais detalhada dos motivos disto não é o objetivo deste trabalho, mas pode-se afirmar que este é mais um caso de diferença que ocorre entre o trabalho idealizado e o trabalho real [GUÉRIN et al., 2001].

Assim, este trabalho tem como objetivo descrever as limas endodônticas manuais e identificar os riscos de acidentes de deglutição ou aspiração das mesmas, inclusive com a discussão de dois casos clínicos. Será também apresentado como uma simples técnica ergonômica postural, e principalmente, como um recurso de design já existente na lima endodôntica pode auxiliar para se evitar este tipo de acidente.

Considera-se este trabalho relevante devido à falta de uma literatura específica e mais detalhada sobre o assunto, e também pela real necessidade de um maior esclarecimento, discussão e conscientização dos profissionais da área.

Realização:




\section{$16^{\circ}$ \\ ERGODESIGN USIHC CINAHPA}

\section{Materiais e Métodos}

Neste trabalho o principal método aplicado foi o descritivo, associado a uma técnica de pesquisa exploratória (documentação indireta), tendo sido realizada pesquisa documental e bibliográfica.

O trabalho foi também complementado pela realização de observações in loco em um consultório odontológico, auxiliado pela realização de registros fotográficos, tanto dos instrumentos utilizados quanto pela observação da prática operacional simulada. Na pesquisa não ocorreu o contato direto com pacientes em tratamento.

\section{Fundamentação}

A endodontia é uma especialidade da Odontologia que trata o dente internamente, em situações de lesões, doenças da polpa (nervo) e da raiz do dente, popularmente conhecido como tratamento de canal. O tratamento consiste na remoção do tecido mole (polpa) que se encontra na parte interna (canal) do dente, que pode estar vivo, sadio, inflamado, infectado ou necrosado (morto), dando continuidade com os procedimentos de instrumentação, até a fase de obturação do(s) canal(is) radicular(es).

$\mathrm{Na}$ endodontia, para o desempenho das funções, são também usados instrumentos manuais de forma rotineira. Muitas vezes, pela falta de recursos financeiros, principalmente em atendimento público, não é possível o uso do lençol de borracha. Este recurso propicia uma maior proteção quanto ao impedimento de contaminação do meio onde desempenha o trabalho no(s) canal(is) radicular(es), evita que produtos de irrigação do(s) canal(is) caiam na boca do paciente, assim como impedi que objetos usados no trabalho caiam na cavidade oral, o que pode acarretar a deglutição ou a aspiração destes elementos.

Porém, existem situações que o próprio meio não permite o uso desse dispositivo, por exemplo, numa situação de grande edema em que a pessoa é impossibilitada a abrir a boca de tal forma para colocação dessa proteção, ou o dente se encontra com certa destruição que inviabiliza a adaptação de $16^{\circ}$ Ergodesign - Congresso Internacional de Ergonomia e Usabilidade de Interfaces Humano Tecnológica: Produto, Informações Ambientes Construídos e Transporte

$16^{\circ}$ USIHC - Congresso Internacional de Ergonomia e Usabilidade de Interfaces Humano Computador

CINAHPA | 2017 - Congresso Internacional de Ambientes Hipermídia para Aprendizagem. grampo, ou o paciente é criança que não colabora para colocação do lençol de borracha.

A lima endodôntica manual em aço inoxidável é um dos instrumentos básicos utilizados no tratamento endodôntico. Seu uso se dá especificamente no escalonamento, que demanda o uso sequencial de variadas limas, dependendo do canal radicular.

Então, pressupõe-se que a probabilidade do risco seja mais constante pelo fato de manusear um número maior de um único tipo de objeto nas determinadas séries, sendo no mínimo doze limas: seis da primeira série e seis da segunda série.

Recomenda-se tomar o devido cuidado, associando ao objeto principal da endodontia, isto é, a lima endodôntica manual, o fio dental amarrado no cabo desta [SARAF et al., 2012; BONDARDE et al., 2015]. Dessa forma, possibilita-se maior segurança e proteção ao paciente, além de se evitar futuros desconfortos ao profissional quanto a eventuais ações judiciais decorrentes de acidentes.

Frente a uma fatalidade, qual seja, a queda da lima dentro da boca do paciente durante o procedimento endodôntico causando um acidente, poderá acarretar risco de vida àqueles em atendimento geralmente devendo submeter-se a procedimentos hospitalares. No que diz respeito, por exemplo, ao objeto que cai em região de orofaringe, este pode seguir a via digestória (deglutição) ou a respiratória (aspiração), devendo ser localizado e monitorado o objeto por meio de exame radiográfico, dependendo da via onde se encontra, se digestiva ou respiratória, sendo que "a deglutição é mais frequente" [SILVA et al., 2010a].

\section{Resultados e Discussões}

\subsection{Evolução do design do cabo}

Através de uma pesquisa no banco de dados de patentes dos Estados Unidos (United States Patent and Trademark Office - USPTO), é obtida uma breve amostra da evolução do design da lima endodôntica (Figura 1). Esta não foi uma pesquisa extensiva, sendo focada na verificação do design 


\section{$16^{\circ}$ \\ ERGODESIGN USIHC CINAHPA}

do cabo da lima e do surgimento do orifício no mesmo, principalmente nas décadas de $1970 \mathrm{e}$ 1980 , momento onde as bases para o formato atual se estabeleceram.

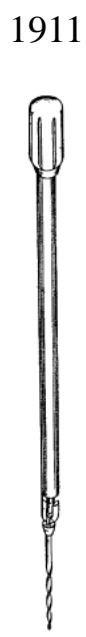

(a)

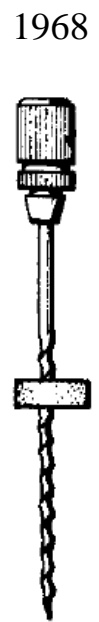

(b)

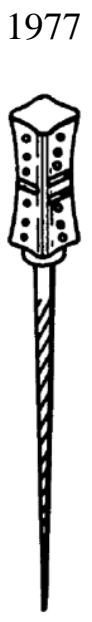

(c)

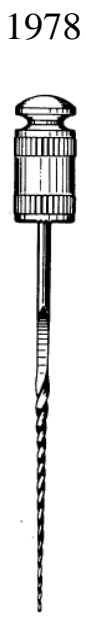

(d)
1981

1981

1985

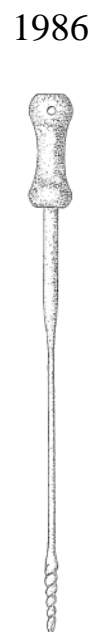

(h)
1989

(i)

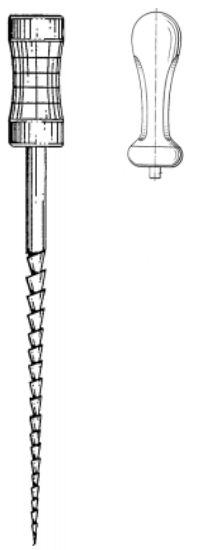

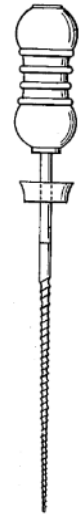

(e)

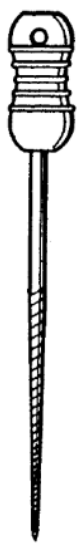

(k)

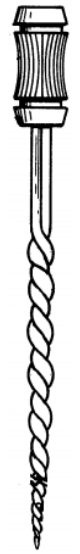

(f)

1991

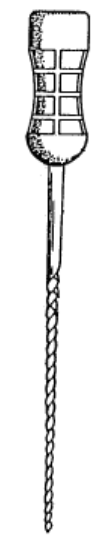

(g) (j)

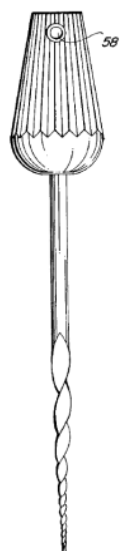

(l)
Figura 1: Exemplos da evolução do design do cabo de limas endodônticas ou correlatos (sem escala). Fonte: adaptado de (a) [POWERS, 1911]; (b) [LORAN, 1968];

(c) [KAHN, 1977]; (d) [LEONARD, 1978]; (e) [JOHNSEN, OIEN, 1981]; (f) [GROVES, LENTINE, 1981]; (g) [ROANE, 1985]; (h) [MATSUTANI, 1986];

(i) [BUCHANAN, 1989]; (j) [LEVY, 1989]; (k)

[SCHILDER, 1989]; e (l) [BUCHANAN, 1991].

Na Figura 1a, apresenta-se uma peça de 1911 que na verdade não era uma lima propriamente dita. Ela se constitui num cabo com uma haste, onde a $16^{\circ}$ Ergodesign - Congresso Internacional de Ergonomia e Usabilidade de Interfaces Humano Tecnológica: Produto, Informações Ambientes Construídos e Transporte

$16^{\circ}$ USIHC - Congresso Internacional de Ergonomia e Usabilidade de Interfaces Humano Computador

CINAHPA | 2017 - Congresso Internacional de Ambientes Hipermídia para Aprendizagem.

ponta seria removível, e o profissional poderia usar a peça com o complemento que assim desejasse, inclusive para funcionar como uma lima.

Já na Figura 1b, de 1968, uma lima que já trazia o cursor. Na Figura 1c, de 1977, tem-se um design de lima com grande preocupação quanto a pega do cabo. A lima da Figura 1e, de 1981, se assemelha bastante às limas modernas, mas ainda não identifica qualquer orifício.

Em 1986, Figura 1h, a peça já traz um orifício junto ao cabo. A Figura 1j, de 1989 é oriunda de uma patente dedicada exclusivamente ao design do cabo. Ainda em 1989, Figura 1k, a lima além de se assemelhar com a lima moderna também possui o orifício, mas nenhum comentário é feito sobre a finalidade do orifício no texto da patente.

Entretanto, em 1991, Figura 11, apresenta-se outro modelo de lima também com o orifício, mas cuja patente tanto identifica isoladamente o orifício, como também registra sua finalidade.

\subsection{Descrição da lima moderna}

Conforme visto, a lima endodôntica se assemelha a uma agulha com "ranhuras cortantes", possuindo variados tamanhos e diâmetros. A lima endodôntica moderna para tratamento convencional é constituída basicamente pelo cabo, que possui um orifício, pelo cursor, haste (com tamanho variável) e parte ativa (medindo $16 \mathrm{~mm}$ ).

São geralmente feitas de aço inoxidável, podendo também ser fabricadas em níquel e titânio. As limas podem ser de vários tipos, tais como Kerr, Flexofile e Hoedstroem. As limas também são classificadas de acordo com sua flexibilidade, guia de penetração e secção transversal.

Em relação à secção transversal, as limas endodônticas podem possuir as mais diversas geometrias, mas as mais comuns são a triangular, a quadrangular e a em forma de vírgula.

Na Figura 2 apresenta-se uma lima endodôntica manual moderna com a identificação de suas partes básicas, e na Figura 3 exemplos de secções transversais.
Realização:
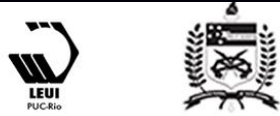


\section{Orifício}

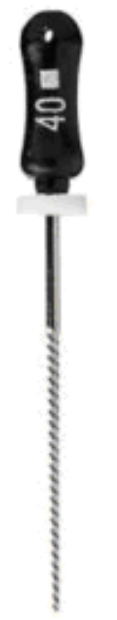

\section{$\rightarrow$ Cabo \\ $\rightarrow$ Cursor \\ $\rightarrow$ Haste}

$\rightarrow$ Parte ativa
Figura 2: Uma lima endodôntica manual convencional moderna com a identificação de suas partes básicas.

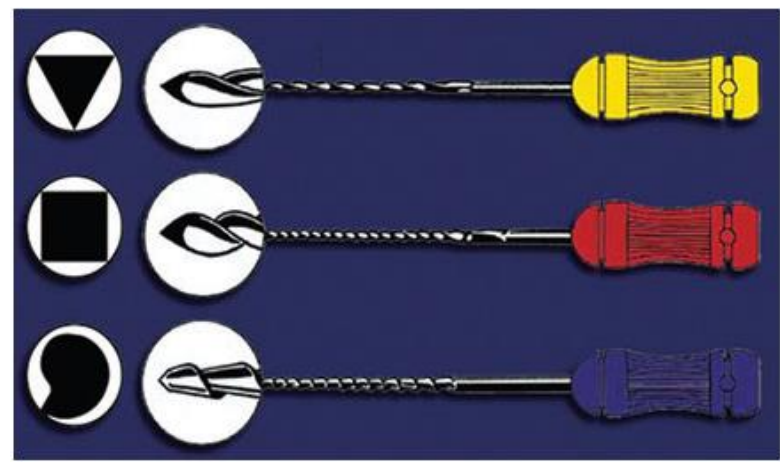

Figura 3: Exemplos de secções transversais de limas endodônticas manuais. Fonte: adaptado de [SHIVAKUMAR; KALGERI, 2016].

O número de identificação da lima corresponde ao seu diâmetro inicial (mm). As limas são classificadas em três séries e cada série é composta por seis limas. Há também uma série especial com três limas de menores diâmetros.

Durante o tratamento são normalmente usadas as limas nas sequências da numeração das séries, selecionando também o tamanho da lima dependendo do dente e dos canais radiculares, guiando-se através de cursor junto a lima, o comprimento de trabalho, durante a instrumentação em escalonamento. Na Tabela 1 apresenta-se o número de identificação das séries de limas endodônticas. $16^{\circ}$ Ergodesign - Congresso Internacional de Ergonomia e Usabilidade de Interfaces Humano Tecnológica: Produto, Informações Ambientes Construídos e Transporte

$16^{\circ}$ USIHC - Congresso Internacional de Ergonomia e Usabilidade de Interfaces Humano Computador

CINAHPA | 2017 - Congresso Internacional de Ambientes Hipermídia para Aprendizagem.

Tabela 1: Número de identificação das séries de limas endodônticas manuais.

\begin{tabular}{|c|c|c|c|c|}
\hline \multirow{2}{*}{ Cor } & \multicolumn{4}{|c|}{ Número de Identificação } \\
\cline { 2 - 5 } & $\begin{array}{c}\text { Série } \\
\text { especial }\end{array}$ & $\mathbf{1}^{\mathbf{a}}$ série & $\mathbf{2}^{\mathbf{a}}$ série & $\mathbf{3}^{\text {a }}$ série \\
\hline $\begin{array}{c}\text { Cor não } \\
\text { especificada } \\
\text { (usualmente rosa) }\end{array}$ & 06 & - & - & - \\
\hline $\begin{array}{c}\text { Cor não } \\
\text { especificada } \\
\text { (usualmente cinza) }\end{array}$ & 08 & - & - & - \\
\hline Roxo & 10 & - & - & - \\
\hline Branco & - & 15 & 45 & 90 \\
\hline Amarelo & - & 20 & 50 & 100 \\
\hline Vermelho & - & 25 & 55 & 110 \\
\hline Azul & - & 30 & 60 & 120 \\
\hline Verde & - & 35 & 70 & 130 \\
\hline Fonto & - & 40 & 80 & 140 \\
\hline
\end{tabular}

Fonte: adaptado de [METZGER et al., 2011].

A Figura 4 e Figura 5 auxiliam a melhor visualizar o uso do fio dental nas limas endodônticas.

Na Figura 4a, apresenta-se o cabo de uma lima endodôntica manual, onde se verifica a existência do orifício no design do cabo, no qual pode ser conduzido um fio dental por este e depois amarrado.

Já a Figura 4b, ilustra o profissional passando o fio dental pelo orifício do cabo da lima. Esta é uma conduta recomendada [SARAF et al., 2012; BONDARDE et al., 2015] a ser praticada de forma individual por cada profissional para maior proteção ao paciente, mesmo em se fazendo o uso do lençol de borracha.

Na Figura 5 apresentam-se todas as limas da série especial (três limas), da primeira série (seis limas) e da segunda série (seis limas), conforme apresentado na Tabela 1. Todas as limas da série especial e da primeira série estão com o fio dental atravessando seu orifício.
Realização:
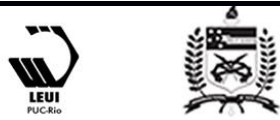


\section{$16^{\circ}$ \\ ERGODESIGN USIHC CINAHPA}

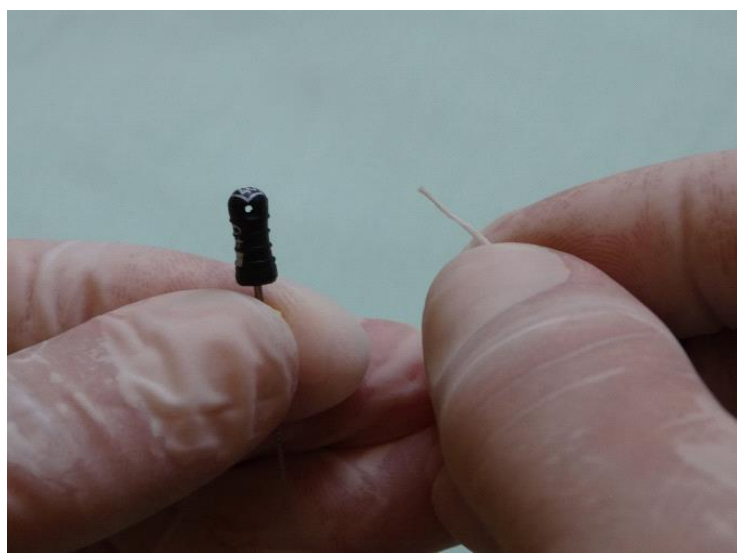

(a)

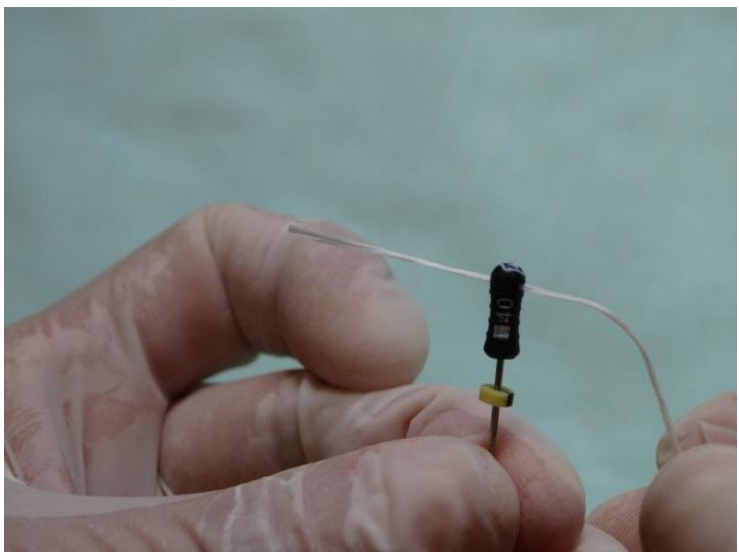

(b)

Figura 4: Em (a) o cabo da lima com o orifício, e em (b) o profissional passando o fio dental pelo mesmo. Fonte: Arquivo Pessoal.

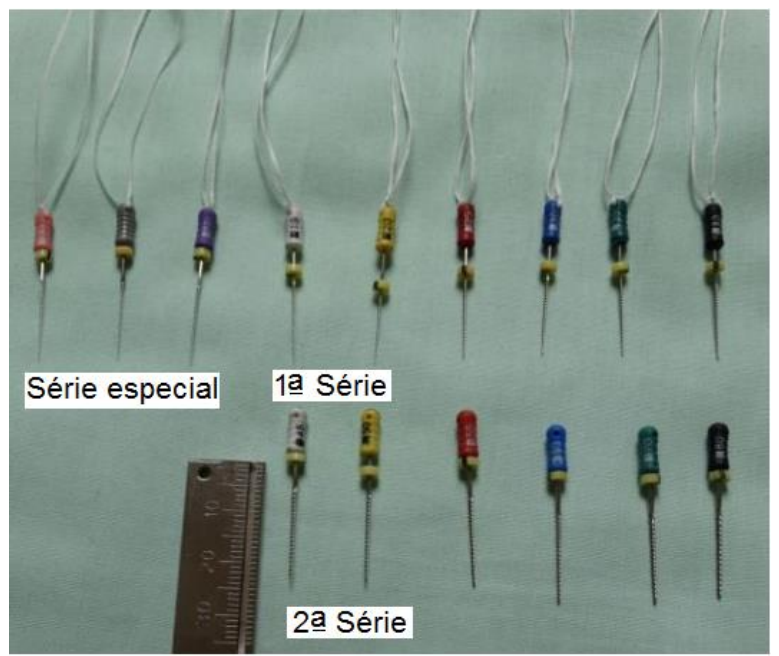

Figura 5: Imagem das limas da série especial, da $1^{\mathrm{a}}$ série e da $2^{\mathrm{a}}$ série. Fonte: Arquivo Pessoal. $16^{\circ}$ Ergodesign - Congresso Internacional de Ergonomia e Usabilidade de Interfaces Humano Tecnológica: Produto, Informações Ambientes Construídos e Transporte

$16^{\circ}$ USIHC - Congresso Internacional de Ergonomia e Usabilidade de Interfaces Humano Computador

CINAHPA | 2017 - Congresso Internacional de Ambientes Hipermídia para Aprendizagem.

\subsection{Casos clínicos de acidentes}

a) Adaptado de [TAVARGERI et al., 2013]:

Departamento de Odontologia Pediátrica, queixando-se de dor e inchaço na cavidade oral na parte inferior direita posterior da mandíbula desde 4 dias. Exame intra-oral revelou cárie dentária profunda em relação ao segundo pré-molar inferior, associado ao inchaço gengival com o mesmo. Após exame radiográfico foi feito um diagnóstico de abscesso periapical agudo.

O paciente era aparentemente cooperativo, e assim, foi feita uma drenagem do abcesso por meio de cavidade, com cobertura de antibióticos. Não foi possível a aplicação do lençol de borracha devido ao inchaço. Durante a extirpação da polpa com uma lima endodôntica, a criança sentiu dor e, de repente, se movimentou de forma brusca, levando ao deslizamento da lima manuseada pelos dedos operadores, que foi engolida pelo paciente.

Todo o protocolo de emergência para recuperar objetos estranhos aspirados foi realizado, incluindo bater na parte de trás, posição de Trendelenburg e manobra de Heimlich. A criança foi imediatamente examinada e não havia sinais de obstrução respiratória (dispnéia ou cianose).

A criança foi levada à sala de urgência do Departamento de Radiologia onde foi feita radiografia anterior-posterior do tórax e do abdome, meia hora após o incidente. A lima foi localizada pelo raio-X (Figura 6) no estômago, e foi decidida pela recuperação desta por meio de gastroendoscopia para evitar mais complicações, considerando que a lima é um instrumento endodôntico afiado.

No exame foi localizada a lima que havia perfurado o revestimento da mucosa na região do esfíncter pilórico, e assim, foi possível a sua recuperação por meio de pinça com sucesso. No dia seguinte, o paciente foi liberado sem quaisquer complicações pós-operatórias
Realização:
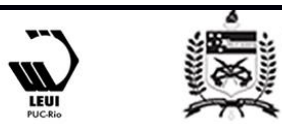


\section{$16^{\circ}$ \\ ERGODESIGN USIHC CINAHPA}

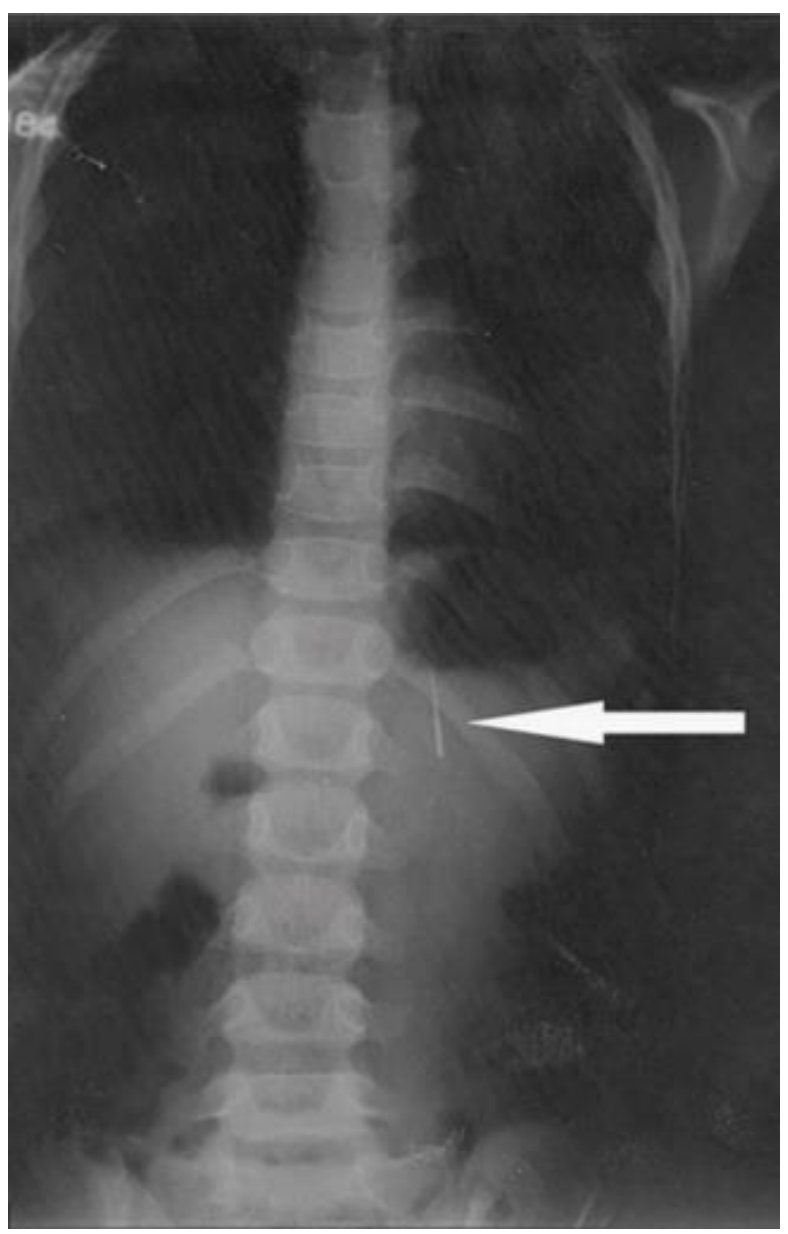

Figura 6: Radiografia torácica revelando a lima endodôntica em região gástrica. Fonte: [TAVARGERI et al., 2013].

b) Adaptado de [SARAF et al., 2012]:

Uma mulher de 38 anos foi ao Departamento de Odontologia Conservativa e Endodontia se queixando, principalmente, de dor no primeiro molar inferior esquerdo. Em exame clínico, observou-se que este dente estava cariado e, em avaliação radiográfica, também foi constatado que a cárie envolvia a polpa, de modo que o rotineiro tratamento do canal radicular foi realizado.

A abertura de acesso foi feita sob a aplicação do lençol de borracha. No entanto, o instrumento foi retirado para a realização de uma radiografia e, de repente, a paciente sentiu ânsia de vômito, depois tossiu e se moveu. $16^{\circ}$ Ergodesign - Congresso Internacional de Ergonomia e Usabilidade de Interfaces Humano Tecnológica: Produto, Informações Ambientes Construídos e Transporte

$16^{\circ}$ USIHC - Congresso Internacional de Ergonomia e Usabilidade de Interfaces Humano Computador

CINAHPA | 2017 - Congresso Internacional de Ambientes Hipermídia para Aprendizagem.
Durante a tosse, a lima Kerr $\mathrm{n}^{\circ} 15$, que estava sendo usada no tratamento do canal, escorregou na boca e foi engolida pela paciente,

inconscientemente. Ela engasgou e teve a sensação de que algo colava em sua garganta. Então, foi instruída a tossir vigorosamente, mas, mesmo assim, a lima não pode ser recuperada. Exame com depressor de língua foi feito, mas sem sucesso.

Não havia evidências do comprometimento das vias aéreas, dificuldade respiratória ou dor abdominal.

Após informada sobre o acidente, a paciente foi levada ao Departamento de Radiologia, onde radiografias abdominal e torácica foram feitas. $\mathrm{Na}$ radiografia do abdome, a lima foi detectada, sugerindo sua presença no trato intestinal no nível lombossacral (Figura 7).

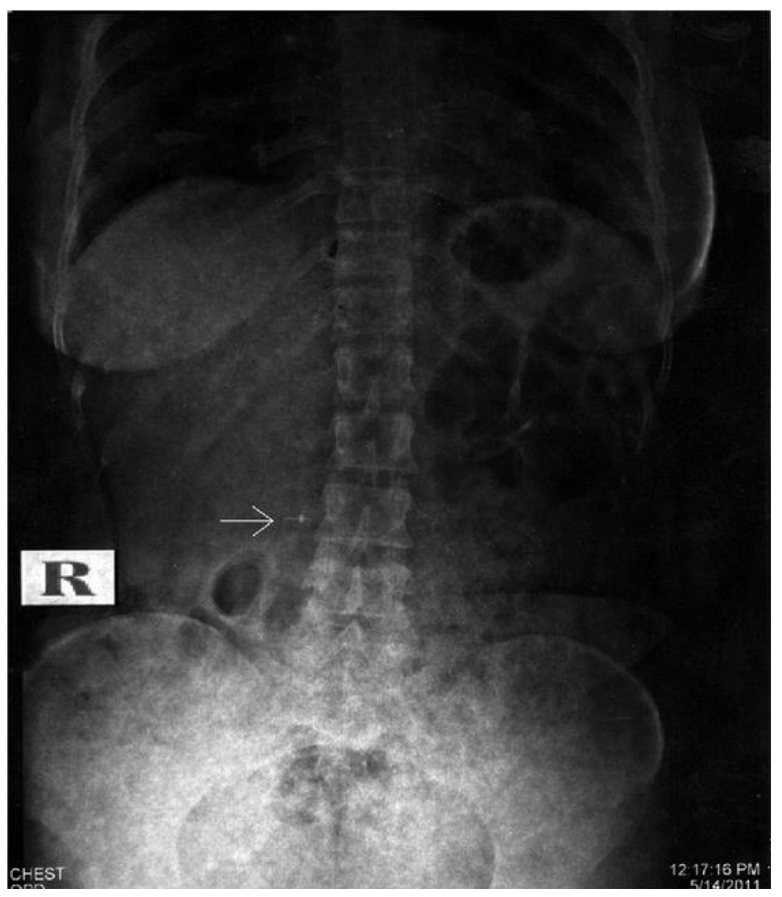

Figura 7: Radiografia do abdome após meia hora, mostrando a lima na região lombossacral do intestino. Fonte: [SARAF et al., 2012].

A paciente foi informada e tranquilizada. Assim, uma dieta rica em fibra foi prescrita para auxiliar a passagem do instrumento pelo trato intestinal. Ela foi avisada sobre os possíveis sintomas que poderiam indicar uma perfuração do intestino e, ainda, foi-lhe dito para examinar suas fezes em 


\section{$16^{\circ}$ \\ ERGODESIGN USIHC CINAHPA}

cada evacuação. A paciente foi mantida em observação e o progresso dela foi acompanhado por uma radiografia abdominal no terceiro dia. Até então, a paciente não havia apresentado sintomas, como sangue nas fezes e sensibilidade abdominal

Uma nova radiografia abdominal evidenciou a ausência da lima, sugerindo que o objeto havia sido eliminado. A paciente estava tranquila, e o tratamento do canal foi concluído.

\subsection{Aspectos ergonômicos posturais}

A postura pode ser considerada como normalmente o fator mais importante no dimensionamento do espaço de trabalho [IIDA, 2010]. No consultório odontológico as questões ergonômicas têm uma importância fundamental. A atividade odontológica é muito exigente do ponto de vista físico, sendo comum o relato da ocorrência de casos de Distúrbios Osteomusculares Relacionados ao Trabalho - DORT em cirurgiões-dentistas. Assim, esta é uma classe de profissionais considerada vulnerável a estes riscos ocupacionais [GARBIN et al., 2009].

Apesar da importância para o profissional, as questões ergonômicas posturais do paciente também devem ser consideradas, pois podem facilitar o trabalho a ser desenvolvido e minimizar riscos.

No caso específico do escopo deste trabalho, a posição postural do paciente na cadeira odontológica pode contribuir na segurança contra a deglutição ou aspiração de corpos estranhos. Estando o paciente ...

"na posição supina o istmo das fauces fica fisiologicamente obliterado, pois a musculatura supra-hióidea e a ação da gravidade tracionam a base da língua para baixo, promovendo essa obliteração" [NARESSI et al., 2013, p. 45].

A Figura 8 auxilia no entendimento da vantagem desta posição postural pela visualização dos istmos (setas verdes). $16^{\circ}$ Ergodesign - Congresso Internacional de Ergonomia e Usabilidade de Interfaces Humano Tecnológica: Produto, Informações Ambientes Construídos e Transporte

$16^{\circ}$ USIHC - Congresso Internacional de Ergonomia e Usabilidade de Interfaces Humano Computador

CINAHPA | 2017 - Congresso Internacional de Ambientes Hipermídia para Aprendizagem.

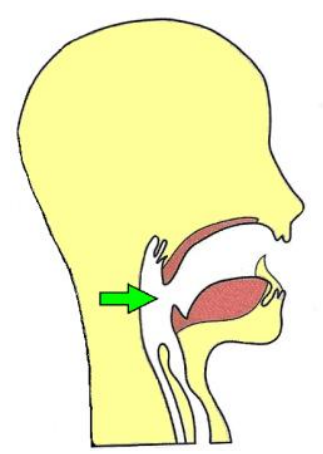

(a)

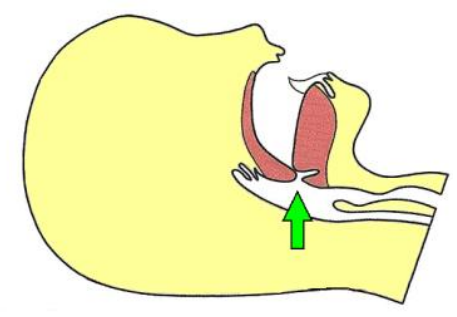

(b)
Figura 8: Istmo das fauces do paciente. Em (a) na posição sentada, e em (b) na posição supina. Fonte: adaptado de [SCHÖN, 1973, p. 37].

A Figura 8a apresenta o istmo das fauces do paciente na posição sentada, enquanto na Figura 8b $\mathrm{o}$ istmo das fauces na posição supina .Observa-se que na figura $8 \mathrm{~b}$, fica dificultada a deglutição ou aspiração, sendo assim esta questão postural um fator extra de segurança.

Entretanto existem situações que, embora o paciente esteja na posição supina, esta não deve ser considerada como um fator de proteção. Isto acontece em situações onde o paciente possui hipersensibilidade na região posterior da língua.

Também podem existir diversas situações em que a posição supina pode não ser recomendada, como no caso de pacientes gestantes a partir do sexto mês de gravidez [NARESSI et al., 2013]. É um dever do profissional realizar uma previa avaliação de cada paciente.

\section{Conclusão}

O ideal é sempre o uso do lençol de borracha. Entretanto, havendo impossibilidade quanto ao seu uso, ou como complementar ao mesmo, existem recursos ergonômicos posturais (paciente na posição supina), e principalmente, a devida utilização do recurso possibilitado pelo design da lima endodôntica que traz um orifício em seu cabo, que podem auxiliar a minimizar acidentes.

Assim, durante o procedimento endodôntico de instrumentação de canal radicular, de modo 


\section{$16^{\circ}$ \\ ERGODESIGN USIHC CINAHPA}

$16^{\circ}$ Ergodesign - Congresso Internacional de Ergonomia e Usabilidade de Interfaces Humano Tecnológica: Produto, Informações Ambientes Construídos e Transporte

$16^{\circ}$ USIHC - Congresso Internacional de Ergonomia e Usabilidade de Interfaces Humano Computador

CINAHPA | 2017 - Congresso Internacional de Ambientes Hipermídia para Aprendizagem. complementar a outros procedimentos indicados, a lima endodôntica, estando associada ao fio dental, ou seja, passando o fio dental por meio de orifício que se encontra no cabo da lima e depois o amarrando (Figura 9), torna a prática mais segura. Se em algum caso de acidente ocorrer uma queda de lima em cavidade oral, na região da orofaringe, a lima poderá ser então resgatada mais facilmente por meio do fio dental.

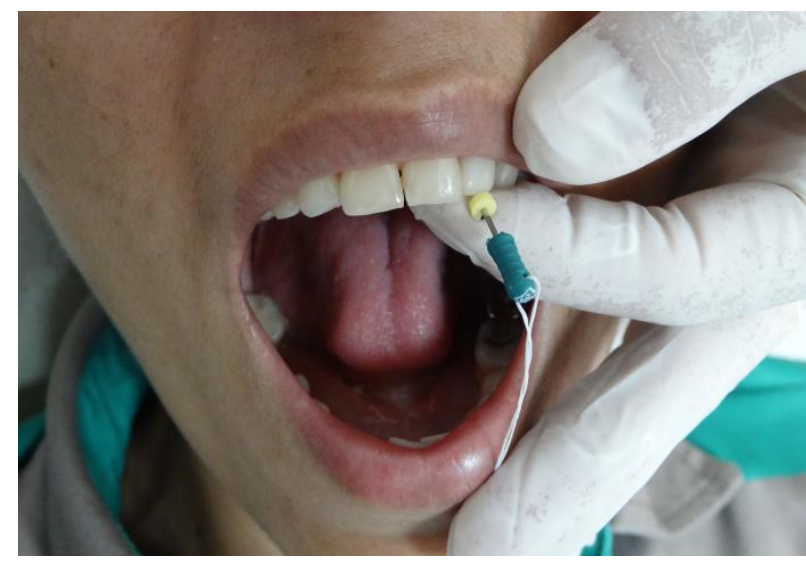

Figura 9: Exemplo de instrumentação de dente usando a lima endodôntica manual com fio dental amarrado. Fonte: Arquivo Pessoal.

Assim, este trabalho detalhou este relevante tema, ensejando um maior esclarecimento e conscientização aos profissionais da área, inclusive facilitando e incentivando futuras discussões.

Uma odontologia preventiva, ética e segura é o que se espera do profissional no desempenho de suas funções. Dessa forma, é preciso ter o devido cuidado quanto a evitar riscos e acidentes ocasionados durante os procedimentos no tratamento do paciente, especificamente ao que permeia a endodontia nos meandros da atuação, tendo em vista o que norteia os cuidados, no que tange o uso dos objetos durante os procedimentos de instrumentação de canais radiculares. Agindo dessa forma, o trabalho fica mais seguro, minimizando os riscos para o paciente, bem como para o profissional, ficando este, livre de futuros desgastes com processos judiciais e/ou ônus de tratamentos médicos corretivos.

\section{BIBLIOGRAFIA}

BONDARDE, P.; NAIK, A.; PATIL, S.; SHAH, P. $\mathrm{H}$. Accidental ingestion and uneventful retrieval of an endodontic file in a 4 year old child: case report. Journal of International Oral Health, v. 7, n. 2, 2015, p. 74-76.

BUCHANAN, L. S. Anti-curvature Dental Root Canal Shaping File. United States Patent, 1989, 8 p. (USPTO n $\left.{ }^{\circ} 4,836,780\right)$.

BUCHANAN, L. S. Endodontic Treatment System. United States Patent, 1998, 25 p. (USPTO $\left.\mathrm{n}^{\mathrm{o}} 5,836,764\right)$.

CONSELHO FEDERAL DE ODONTOLOGIA. Resolução CFO n ${ }^{\circ} 118$ de 11 de maio 2012. Revoga o Código de Ética Odontológica aprovado pela Resolução CFO-42/2003 e aprova outro em substituição.

DE DEUS, Q. D. Endodontia. MEDSI: Rio de Janeiro, $5^{\text {a }}$ ed., 1992. 695 p.

GARBIN, A. J. Í.; GARBIN, C. A. S.; DINIZ, D. G. Normas e diretrizes ergonômicas em odontologia: o caminho para a adoção de uma postura de trabalho saudável. Revista de Odontologia da Universidade Cidade de São Paulo, v. 21, n. 2, 2009, p. 155-161.

GROVES, W. A. Endodontic Instrument. United States Patent, 1981, 4 p. (USPTO n 4,260,379).

GUÉRIN, F.; LAVILLE, A.; DANIELLOU, F.; DURAFFOURG, J.; KERGUELEN, A.

Compreender o Trabalho para Transformá-lo: a prática da ergonomia. Edgard Blücher: São Paulo, 2001, 200 p.

IIDA, I. Ergonomia: Projeto e Produção. Edgard Blücher: São Paulo, $2^{a}$ ed., $2^{a}$ reimp., 2010, 614 p.

JOHNSEN, J. B.; OIEN, H. J. Endodontic File Holder. United States Patent, 1981, 6 p. (USPTO $\left.n^{\circ} 4,280,808\right)$.

KAHN, H. Handle for Cutting and Abrading Intruments Useful in the Practice of
Realização:

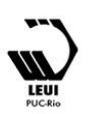




\section{$16^{\circ}$ \\ ERGODESIGN USIHC CINAHPA}

Endodontia. United States Patent, 1977, 4 p. (USPTO 4,044,468).

KATAOKA, S. H. H.; MOREIRA, F.; BOUTTEVILLE, L.; CALDEIRA, C. L.; PESSOA, O. F. Deglutição acidental de uma lima Protaper ${ }^{\circledR}$ durante o tratamento do canal. Dental Press Endod., v. 1, n. 2, 2011, p. 89-93.

KHERI, P.; SINHA, N.; DABAS, U.; DABAS < V. $\mathrm{K}$. Accidental ingestion and successful retrieval of an endodontic file from the left hypochondriac region using endoscopy. Endodontology, v. 28, n. 2, 2016, p. 183-187.

LAMBRIANIDIS, T.; BELTES, P. Accidental swallowing of endodontic instruments.

Endodontics \& Dental Traumatology, v. 12, 1997, p. 301-304.

LEONARD, H. Dental Root-canal Broach. United States Patent, 1978, 2 p. (USPTO Des. N ${ }^{\circ}$ 250,544).

LEVY, G. Manually Operated Endodontic Instrument. United States Patent, 1989, 4 p. (USPTO n 4,824,369).

LORAN, W. Depth Control and Direction Indicating Device for Endodontic Operations. United States Patent Office, 1968, 4 p. (USPTO n ${ }^{\circ}$ $3,388,473)$.

MATSUTANI, K. Dental Reamer. United States Patent. 1986, 2 p. (USPTO Des. no 283,840).

METZER, Z.; BASRANI, B. \& GOODIS, H.E. Instrumentos, materiais e aparelhos. Cap. 8. In: Caminhos da Polpa, Eds. HARGREAVES, K. M. \& COHEN, S., $10^{\mathrm{a}}$ ed., Rio de Janeiro: Elsevier, 2011, 928p.

NARESSI, W. G.; ORENHA, E. S.; NARESSI, S. C. M. Ergonomia e Biossegurança em Odontologia. Artes Médicas: São Paulo, 2013, 128 p. (Odontologia Essencial - Parte Clínica).

POLETO, C. A. R.; TANAKA, O. M.; GEVAERD, R.; POLETTO, C. G.; CAMARGO, E. S. Prevenção e conduta diante da ingestão e $16^{\circ}$ Ergodesign - Congresso Internacional de Ergonomia e Usabilidade de Interfaces Humano Tecnológica: Produto, Informações Ambientes Construídos e Transporte

$16^{\circ}$ USIHC - Congresso Internacional de Ergonomia e Usabilidade de Interfaces Humano Computador

CINAHPA | 2017 - Congresso Internacional de Ambientes Hipermídia para Aprendizagem.

deglutição acidental de componentes dos aparelhos ortodônticos. Rev Clin Ortod Dental Press, v. 12, n. 1, 2013, p. 66-72.

POWERS, C. R. Dental Tool-holder. United States Patent Office, 1911, 3p. (USPTO n ${ }^{\circ}$ 993,100).

PRATS, L. D. Disciplina de Endodontia: uma análise a partir da ótica de docentes e discentes de odontologia. Escola Paulista de Medicina Universidade Federal de São Paulo, 2005, 128 p. (Dissertação de Mestrado).

ROANE, J. B. Endodontic Instrument. United States Patent, 1985, 10 p. (USPTO n 4,536,159).

RODRIGUES, A. J.; OLIVEIRA, E. Q.; SCORDAMAGLIO, P. R.; GREGÓRIO, M. G.; JACOMELLI, M.; FIGUEIREDO, V. R.

Broncoscopia flexível como primeira opção para a remoção de corpo estranho das vias aéreas em adultos. Jornal Brasileiro de Pneumologia, v. 38, n. 3, 2012, p. 315-320.

ROVIDA, T. A. S. \& GARBIN, C. A. S. Noções de Odontologia Legal e Bioética. São Paulo: Artes Médicas, 2013, 143 p.

SARAF, H. P.; NIKHADE, P. P.; CHANDAK, M. G. Accidental ingestion of endodontic file: a case report. Case Report in Dentistry, v. 2012, 2012, 3 p. Article ID 278134.

SCHILDER, H. Set of Endodontic Instruments. United States Patent, 1991, 5 p. (USPTO ${ }^{\circ}$ $5,017,138)$.

SCHÖN, F. Trabajo em Equipo em la Práctica Odontológica. Berlin: Quintessence Books, 1973.

SHIVAKUMAR, A. T.; KALGERI, S. H.

Peregrination of endodontic tools - past to present. Journal of the International Clinical Dental Research Organization, v. 8, n. 1, p. 89-92.

SILVA, R. F.; FERREIRA, G. M.; LELES, J. L. R.; IWAKI FILHO, L.; DARUGE JÚNIOR, E.

Passagem de corpos estranhos pela orofaringe durante tratamento odontológico: abordagem
Realização:

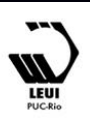




\section{$16^{\circ}$ \\ ERGODESIGN USIHC CINAHPA}

$16^{\circ}$ Ergodesign - Congresso Internacional de Ergonomia e Usabilidade de Interfaces Humano Tecnológica: Produto, Informações Ambientes Construídos e Transporte

$16^{\circ}$ USIHC - Congresso Internacional de Ergonomia e Usabilidade de Interfaces Humano Computador

CINAHPA | 2017 - Congresso Internacional de Ambientes Hipermídia para Aprendizagem.

clínica e odontolegal. Rev. Cir. Traumatol. BucoMaxilo-fac., v. 9, n. 3, 2009, p. 55-62.

SILVA, R. F.; PRADO, F. B.; PORTILHO, C. D. M.; SILVA, R. F.; DARUGE JÚNIOR, E.

Orientações clínicas e éticas em caso de deglutição de corpo estranho durante atendimento odontológico. Revista Sul-Brasileira de Odontologia. v. 7, n. 3, 2010, p. 354-359.

SILVA, R. F.; BARBIERI, L.; PORTILHO, C. D. M.; PRADO, M. M.; DARUGE JÚNIOR, E. Importância das informações prestadas ao paciente antes, durante e depois do tratamento endodôntico: abordagem à luz do Código de Defesa do Consumidor. Revista Sul-Brasileira de Odontologia, v. 7, n. 4, 2010, p. 481-487.

TAVARGERI, A. K.; ANEGUNDI, R. T.; PATIL, S. B.; TRASAD,V.; BATTEPATTI, P. Retrieval of swallowed endodontic file with gastro-scope.

Saudi Endodontic Journal. v. 3, n. 1, 2013, p. 3133. 